\title{
ATLAS OF AIRBORNE PARTICLES FROM KOZANI AREA, NORTHERN GREECE
}

\author{
Iordanidis A. ${ }^{1}$, Buckman $\mathrm{J}^{2}{ }^{\text {, }}$, Triantafyllou A. G. ${ }^{1}$, and Asvesta A. ${ }^{1}$
}

${ }^{1}$ Department of Geotechnology and Environmental Engineering, TEI of Western Macedonia, Kila, 50100 Kozani, Greece, aiordanidis@yahoo.co.uk,atria@teikoz.gr,asvesta@teikoz.gr

${ }^{2}$ Institute of Petroleum Engineering, Heriot-Watt University, Edinburgh Campus, EH14 4AS, Scotland,U.K, Jim.Buckman@pet.hw.ac.uk

\begin{abstract}
During a whole year (March 2003 to February 2004), several filters that capture airborne particles were collected from seven sampling sites spread throughout the Ptolemais-Kozani region (Western Macedonia), northern Greece. Environmental Scanning Electron Microscopy (ESEM), coupled with Energy Dispersive X-Ray analysis (EDX) was employed for the characterisation of the airborne particles. $A$ classification of these airborne particles is attempted in this study. Aerosols with various morphological characteristics (angular, irregular, rounded, spherical, spheroidal, acicular), variable size (mostly between $5 \mu \mathrm{m}$ and $20 \mu \mathrm{m}$ ) and composition (aluminosilicates, oxides, carbonates, sulphates, metallic) were recognized. The airborne particulates were also categorized according to their origin. Geogenic, biogenic, anthropogenic (mainly fly ash released from lignite-fired power plants), carbonaceous and metalliferous (mainly iron and copper enriched) were the main categories. A database of characteristic airborne particles from Kozani area is being created using a simple software package, in order to help similar studies in the future.
\end{abstract}

Key words: SEM/EDX, air pollution, source identification, geogenic, anthropogenic.

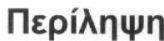

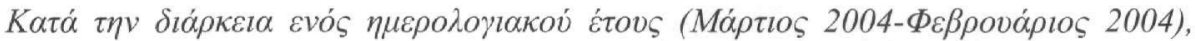

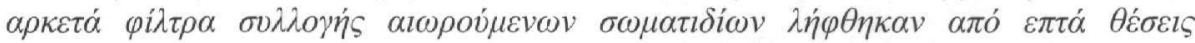

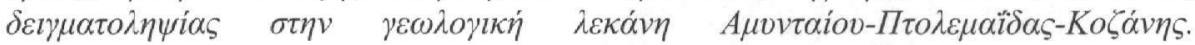

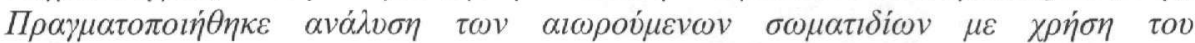

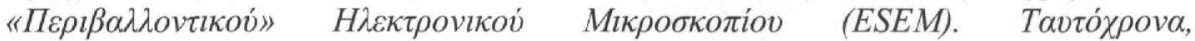

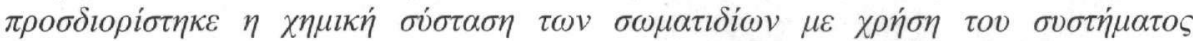

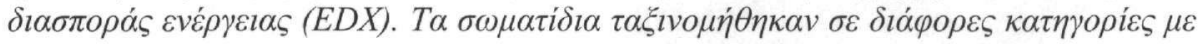

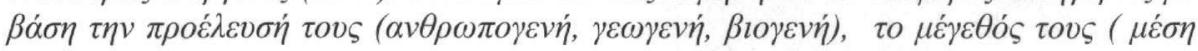

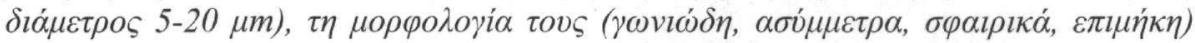

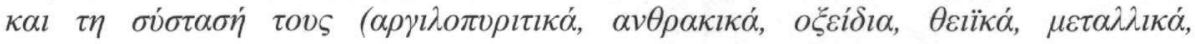

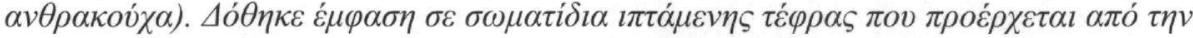

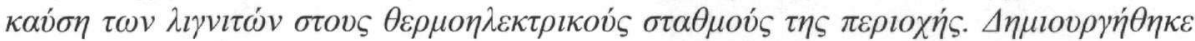

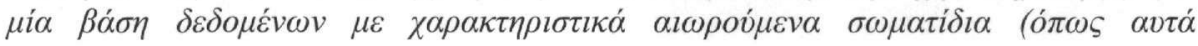




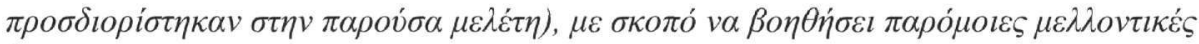
$\varepsilon \dot{\rho} \varepsilon v \vee \varepsilon \varsigma \sigma \tau \eta v \varepsilon \varepsilon \rho \imath \chi \chi \dot{\text {. }}$

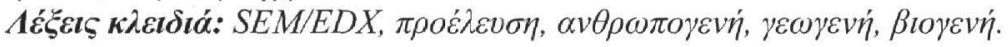

\section{Introduction}

The connection between exposure to airborne particles and its adverse effects on human health have been well investigated (Breed et al. 2002). It is therefore crucial to understand the nature of the particulate matter, especially in areas which suffer from heavy air pollution problems (e.g. industrial territories or urban regions). This could be helpful for the local and national authorities or environmental organisations, in order to assess the environmental impacts of human activities and schedule plans to enhance ecological protection and corroborate with the air pollution problems.

The source identification of aerosols is often based on their morphological, mineralogical and chemical characteristics. For this reason, several multidisciplinary analytical methodologies have been applied, such as X-Ray Fluorescence (XRF), Inductively Coupled Plasma spectroscopy (ICP), Neutron Activation Analysis (NAA), Electron Microprobe (EMPA), Scanning Electron Microscopy (SEM), Transmission Electron Microscopy (TEM) etc. (Paoletti et al. 2002, Ebert et al. 2004, Kupiainen and Tervahattu 2004, Goforth and Christoforou 2006, Suzuki 2006).

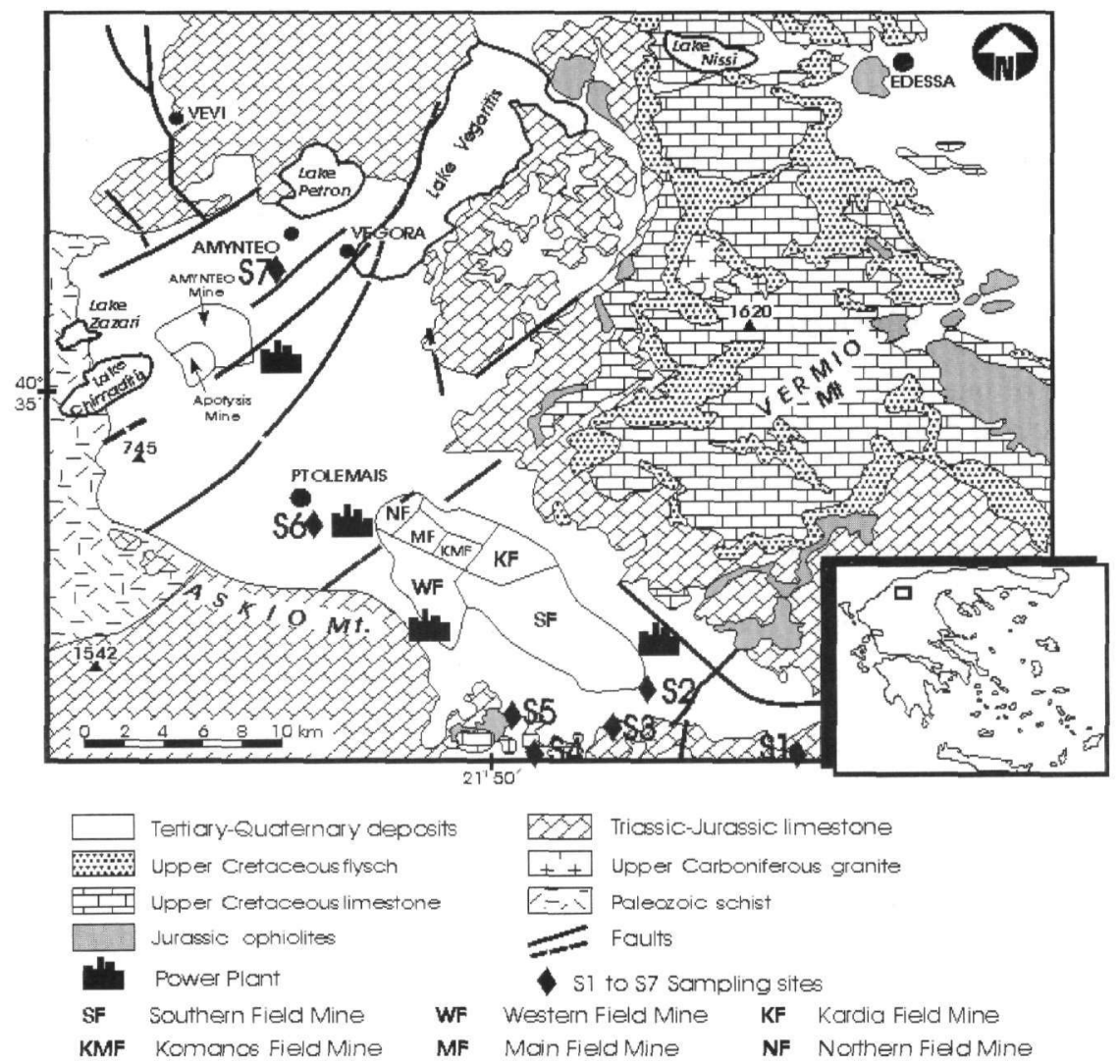

Figure 1 - Simplified geological map of the Ptolemais-Kozani area, showing the seven sampling sites (S1 to S7), the opencast lignite mines and the lignite-fired power-plants

In the Western Macedonia region of northern Greece, heavy air pollution problems have been demonstrated, attributed mainly to the extensive lignite mining and burning for energy production. The investigation of this problem incorporated statistical evaluation of TSP, PM10 and PM2.5 
concentrations, chemical mass balance source apportionment studies and creation of mathematical models based on the meteorological and topographical data (Triantafyllou et al 2002, Samara 2005, Zoras et al. 2006). The present study employs the Environmental Scanning Electron Microscopy (ESEM) technique for the identification of individual airborne particles. Environmental Scanning Electron Microscopy (ESEM) is a special type of scanning electron microscope that works under controlled environmental conditions and does not require a conductive coating on the specimen, thus providing fast results. ESEM, coupled with energy dispersive X-ray analysis (EDX), provides information on individual airborne-particle analysis and reveals definitive information about elemental associations, agglomerations and variation of composition with particle size. A classification of the airborne particles is being attempted, based on their origin and morphological and compositional characteristics.

\section{Sampling area}

The Florina-Ptolemais-Kozani basin (sampling area) is situated within Western Macedonian region (Fig. 1). This basin is $50 \mathrm{~km}$ long and $10-25 \mathrm{~km}$ wide, relatively flat-bottomed at about $650 \mathrm{~m}$ above sea level, surrounded by high mountains. Climate is continental Mediterranean characterized by low temperatures during winter and high temperatures during summer. Prevailing winds are weak blowing mostly along the NW/SE axis of the basin (Samara 2005).

Most of the greek lignite deposits are located in this large, intensively exploited area. This area is exploited by opencast mining and feeds nearby lignite-fired power stations. Five thermal power stations are located in this basin which account for $80 \%$ of the total lignite burning electricity production in Greece. About $64 \mathrm{Mt}$ of lignite, produced by open-cast mining in four mines, are annually used in the power plants leading to an annual fly ash production of nearly $13 \mathrm{Mt}$ (Kantiranis et al. 2006). The area has suffered in the past from high ambient levels of total suspended particles (TSP), although electrostatic filters were used in the power plants.

\section{Materials and Methods}

Over a period of one year (March 2003 to February 2004), data was collected by stationary and portable collectors, placed throughout the region, at seven sampling sites (Fig. 1). The sampling took place on ten randomly chosen dates, covering all seasons. Total suspended particles (TSP) were collected on fibre-glass and cellulose filters, while PM10 and PM2.5 (particulate matter with a diameter lower than $10 \mu \mathrm{m}$ and $2.5 \mu \mathrm{m}$ respectively) on teflon filters. Several square centimeters of filter paper were cut from the centre of each filter paper, and examined within the ESEM without any form of preparation (i.e. no gold or carbon coating). A Philips XL30 environmental scanning electron microscope (ESEM), equipped with a $\mathrm{LaB}_{6}$ filament, was used to image and elementally analyse the filter samples of the present investigation. The ESEM was operated in low-vacuum mode, at a pressure of between 0.5 and 0.7 Torr, under a water vapour atmosphere. Other operational parameters were as follows: working distance $10 \mathrm{~mm}$, and operating voltage 20 $\mathrm{kV}$. Imaging was predominantly carried out in backscattered electron mode (BSE). Elemental analysis was carried out by energy dispersive X-ray analysis (EDX), under the same operational parameters as for imaging. EDX analysis was carried out at each analysis point for 100 live seconds, and the elements present were both qualitatively and quantitatively measured. Approximately five hundred ESEM images and EDX spectra of individual airborne particles were obtained.

\section{Results and Discussion}

Based on the images and chemical analysis of the airborne particles, using the ESEM-EDX equipment, several categories were identified based on their provenance and their morphological and compositional characteristics. Another grouping was also created according to the sampling sites. All these data are being incorporated in a database of airborne particles from the Ptolemais- 
Kozani region, which will be useful for similar studies of local and national authorities, as well as for other scholars working in the region. The aforementioned categorization is schematically demonstrated in Figure 2.

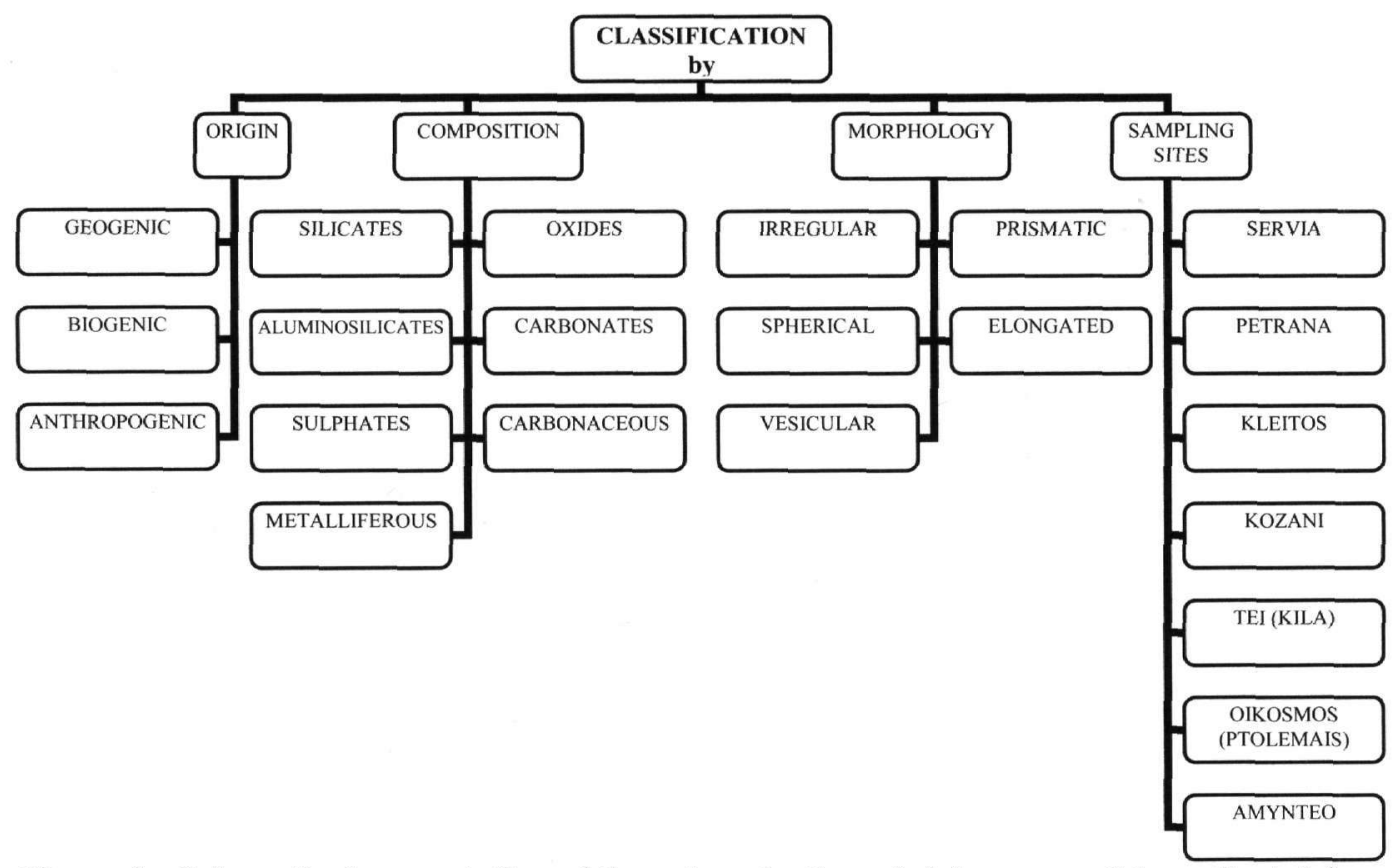

Figure 2 - Schematical presentation of the categorization of airborne particles collected from Ptolemais-Kozani area, northern Greece.

It should be noted however that the majority of the analysed airborne particles consist of aggregates of various composition with a minerogenic (natural) origin. Moreover, the agglomeration of smaller particles often hindered the identification of individual particles.

\subsection{Morphology and size of airborne particles}

The size of the analysed individual airborne particles ranged between $<1 \mu \mathrm{m}$ and $50 \mu \mathrm{m}$. The majority of the particulates captured in TSP filters had a size between $5 \mu \mathrm{m}$ and $20 \mu \mathrm{m}$. PM10 and PM2.5 revealed obviously smaller sizes (fine and ultrafine dimensions). Nevertheless, there were observed a few large particles ( $>10 \mu \mathrm{m}$ and $>2.5 \mu \mathrm{m}$ ) in the PM10 and PM2.5 filters respectively, a fact that suggests inadequate separation of the sampling equipment. According to their morphological characteristics, there were found particulates with an acicular (elongated), prismatic (platy, hexagonal, rhombic, cubic etc.), irregular, rounded, spherical or spheroidal shape, and a dense, porous or vesicular structure. Some of the above mentioned characteristic features are shown in Figure 3. A polygonal crystal, is shown in Figure 3a, a prismatic and an amorphous particle in Fig. 3b, a platy flake in Fig. 3c, a needle-like (acicular) crystal in Fig. 3d, a spherical particle in Fig. 3e and a porous particulate in Fig. 3f. Fine airborne particles with a diameter lower than $10 \mu \mathrm{m}$ are taken into special consideration, since these particles (PM10) are regarded as respirable and may cause damage to the respiratory system of humans. Only a few minute fibre particles were observed, a fact that is significant when thinking of the health impacts of ultrafine fibrous aerosols. Nevertheless, the chemical composition of such particles (e.g. soluble transition metals like iron, titanium or zinc in our study), their acidity and ultrafine size could pose a threat to human health. The latter aspect is discussed below. 

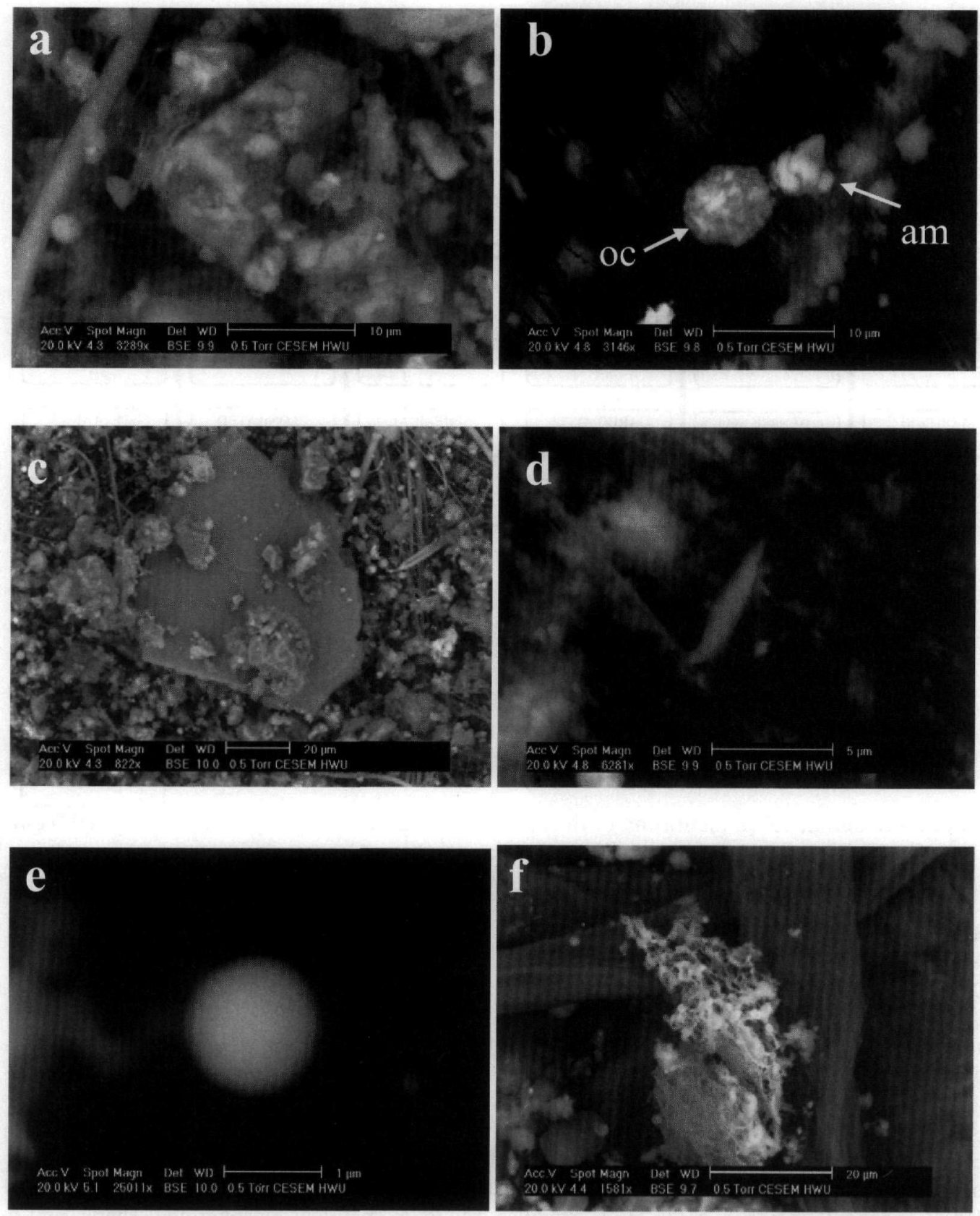

Figure 3 - Classification of airborne particles according to their morphology: a) a polygonal prismatic crystal, b) an octagonal euehdral crystal (oc) and an irregular amorphous particle $(\mathrm{am}), \mathrm{c})$ a platy crystal, d) an acicular, needle-like particle, e) a fine spherical particle, f) a porous (vesicular) aggregate

\subsection{Origin and composition of airborne particles}

The airborne particles of our study could be classified according to their origin (provenance) and composition to the following dominant groups: geogenic particles (mineral fragments, aggregates and agglomerates of various composition derived from soils and weathered rock surfaces); biogenic aerosols (organic plant material, fungal hyphae and spores); fly ash airborne particles (fly 
ash of various morphology and composition, coming from the nearby power plants); metalliferous (anthropogenic) particles.

\subsubsection{Geogenic particles}

Geogenic are mineral particulate aerosols derived from soils, sediments and weathered rock surfaces. The release of natural aerosols due to extensive mining activities in the area contribute greatly to the geogenic airborne particles found in this study. Yet, it is very difficult to distinguish between natural aerosol dust and dust derived from the mine outcrops or transportation of sterile rocks from opencast lignite mines. Some characteristic natural particles are shown in Figure 4. In particular: a rhomboehdric calcite crystal $\left(\mathrm{CaCO}_{3}\right)$ in Fig. $4 \mathrm{a}$ and an elongated quartz crystal $\left(\mathrm{SiO}_{2}\right)$ in Fig. 4b. Several other common geogenic particles were also identified, such as feldspars (Fig. 5a), phyllosilicate minerals (e.g. clays and micas of Fig. 5b), carbonates (Fig. 5c), oxidehydroxides (Fig. 5d) etc., along with some uncommon minerals of probably natural origin (e.g. zircon, titanite, apatite). Fine sulphate particles were also rather abundant. Such sulphates could be regarded as a sampling artifact, originating from the reaction of gaseous pollutants $\left(\mathrm{SO}_{2}\right)$ with the Ca-rich dust particles already collected in the filter. The pathological effects of prolonged exposure to natural aerosol dust have been demonstrated (Derbyshire 2005). Besides, some of the identified minerals are known for health implications. For example, quartz could cause silicosis; clay minerals refer to kaolinosis; and iron carbonate/oxide is connected to siderosis (Jones et al. 2006).

\subsubsection{Bioaerosols}

Biogenic airborne particles, the so-called bioaerosols, have also been observed in our study. Bioaerosols are known as a wide spectrum of dead or alive airborne particles of biological origin, including microorganisms and fragments of all varieties of living matter (i.e. viruses, bacteria, fungal spores, pollen, plant debris and animal matter). Bioaerosols can cause adverse effects on humans, animals and plants (Ryves et al. 2003).

In our study, fragments of valves and frustules of circular, elliptic and square diatoms were recognised, all of terrestrial origin, belonging to Centrophycae and Pennatophycae classes and Aulacoseira and Fragilaria genus. A fragment of diatom frustules belonging to Centrophycae class is shown in Fig. 4c. The identified diatoms are considered as recent ones, derived from surface soils and sediments. Two other less possible sources could be the following: they might have come during strong air movements (episodes) from the outcrops of the opencast lignite mines or the dumping areas of the overburden rocks, where Neogene, diatom-rich sediments are exposed to air (Ognjanova-Rumenova 2003), or they might be present in the lignite, feeding the power plant and due to their composition (biogenic silica) and small size might be released to the atmosphere as fly ash particles. A bunch of fungal spores is shown in Fig. 4d. It is well known that human exposure to airborne fungal spores might cause adverse health effects, especially respiratory symptoms (Liao et al. 2004). Fungal spores were more abundant during late spring-early summer period, while diatoms were observed throughout the year. A spore and/or pollen airborne particle of unknown origin is also shown in Fig. 4e.

\subsubsection{Fly ash particles}

Fly ash particles consist of inorganic amorphous and crystalline constituents. Emphasis was given on the amorphous particles, since it is very difficult to distinguish between geogenic and anthropogenic crystalline particles. Considering that no other heavy industrial activities (e.g. refineries, steel production, blast furnaces, large-scale cement industries) exist in the area, that could produce such airborne pollutants, these amorphous, spherical, inorganic particles are most likely related to fly ash (Lee et al. 2004). The amorphous components consist mostly of spheres and spheroids, although angular and irregular particles are not absent. Characteristic iron-rich plerospheres (i.e. cenospheres that capsulate other smaller pre-existing aggregates, particles and agglomerates) are shown in Fig. 4f and Fig. 5d. The chemical composition of the fly ash-airborne 

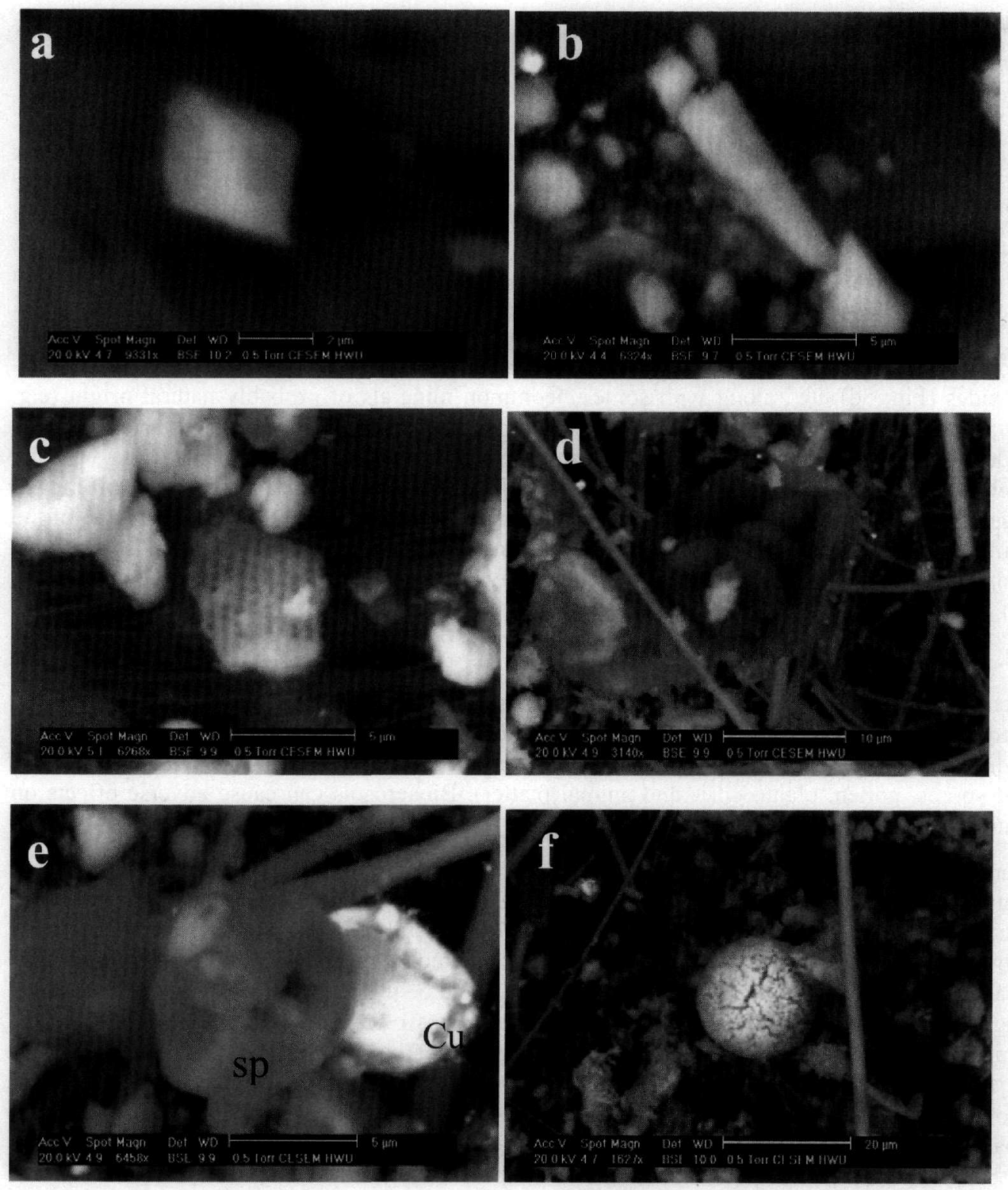

Figure 4 - Classification of airborne particles according to their origin: a) a geogenic rhomboehdral calcite, b) an elongated quartz crystal, c) a fragment of diatom frustules belonging to Centrophycae class (biogenic), d) fungal spores (biogenic), e) a spore/pollen (biogenic) $[s p]$ and a $\mathrm{Cu}$-rich particle (anthropogenic) $[\mathrm{Cu}], \mathrm{f}$ ) a $\mathrm{Fe}-$-rich, fly ash plerosphere (anthropogenic)

particles is mainly aluminosilicates and iron and/or calcium- rich particles. The presence of potential toxic metals (e.g. copper and zinc) in several fine fly ash particles is also evident. In addition, unburnt lignite (char) was observed, which originates from the incomplete combustion of lignite. Similar images of fly ash particles of the same region have been published previously (Georgakopoulos et al. 1992, Fernandez-Turiel et al. 2004, Iordanidis et al. 2005). 

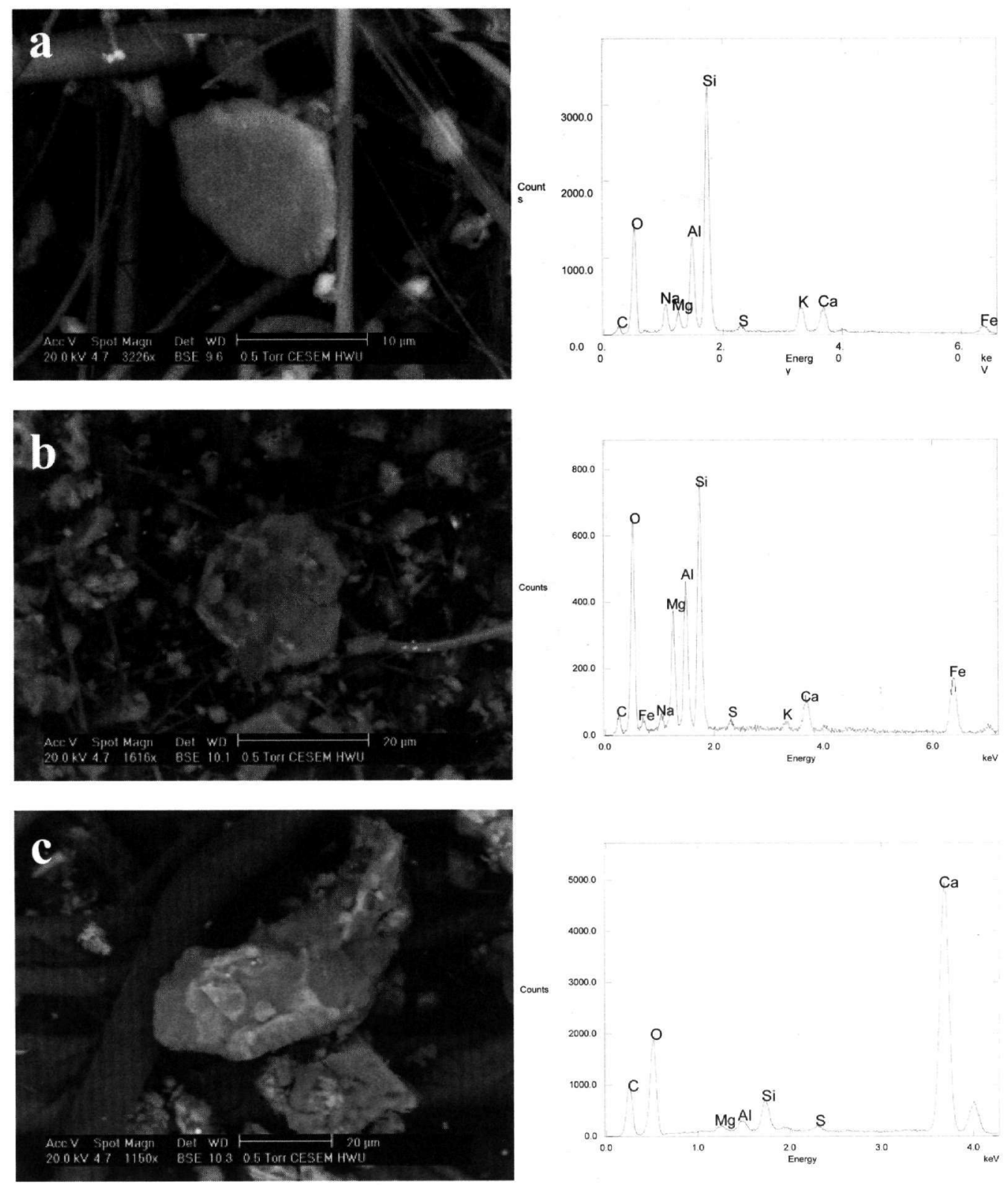

Figure 5 - ESEM images and EDX spectra of airborne particles of different composition: a) a feldspar crystal $\left.\left[(\mathrm{K}, \mathrm{Na}, \mathrm{Ca}) \mathrm{AISi}_{3} \mathrm{O}_{8}\right], \mathrm{b}\right)$ a clay or mica flake, c) a calcium carbonate $\left[\mathrm{CaCO}_{3}\right.$, calcite] particle 

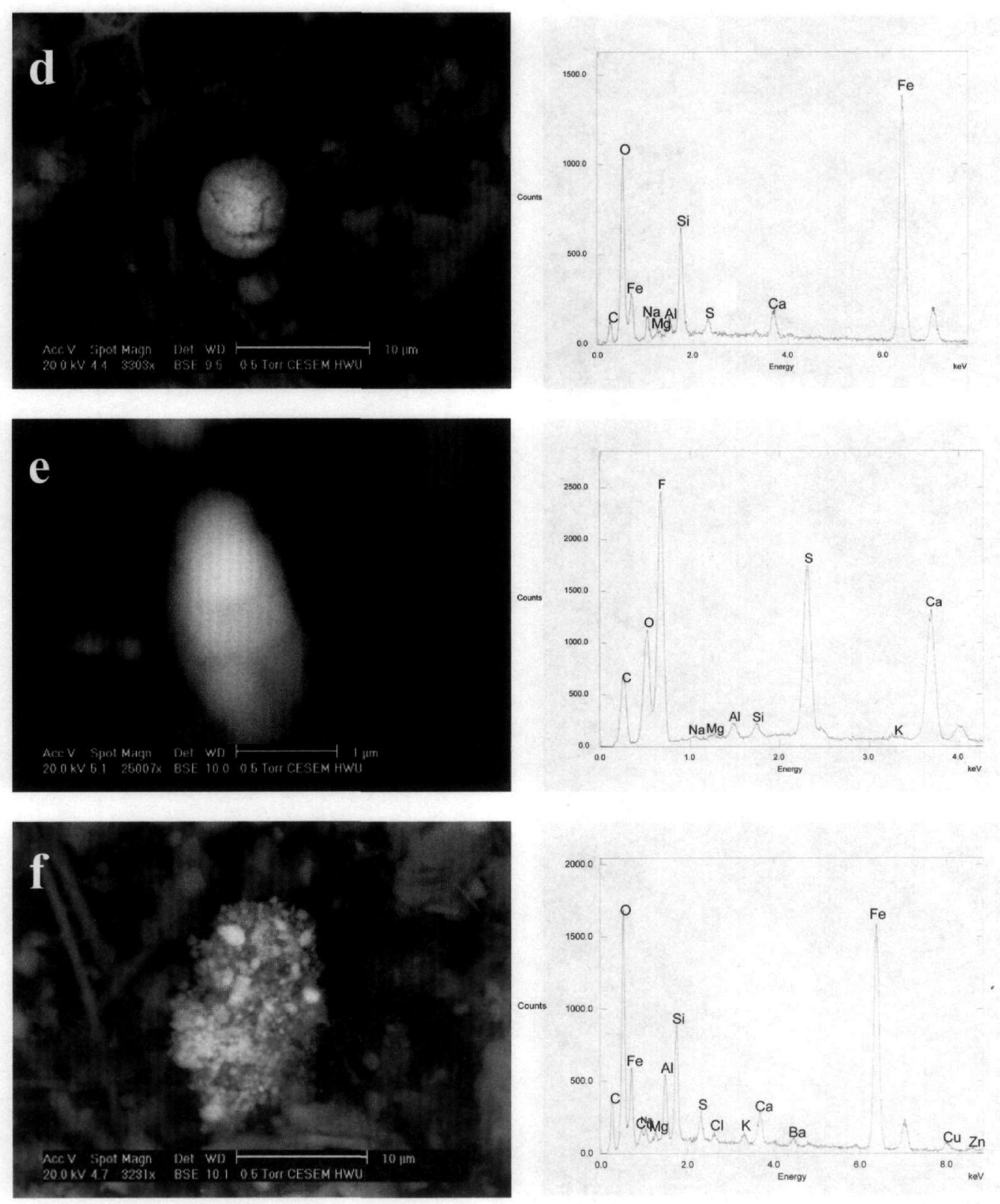

Figure 5 (continued) - ESEM images and EDX spectra of airborne particles of different composition: d) an iron oxide spherical particle, e) an ultrafine sulphate particle, f) an agglomeration of minute Fe-rich particles, with minor amounts of $\mathrm{Cu}$ and $\mathrm{Zn}$ metals

The temporal and spatial distribution of fly ash-airborne particles did not show significant variation. Fly ash was found in all sampling sites (predominantly nearby power stations) and all sampling dates. Fine and ultrafine particles were recorded mainly in remote areas, where they have obviously been transported by the winds (sampling sites S1, S4 and S5). Larger fly ash particles are generally concentrated proximal to power stations (sampling sites S3 and S6).

Several studies have well demonstrated the environmental impacts of the lignite-induced air pollution in the Ptolemais-Kozani area (Stalikas et al. 1997, Kallithrakas-Kontos et al. 1998, Triantafyllou 2001, Samara 2005). A study of the detrimental effects on the respiratory system of 
children residing in Western Macedonia, Greece, has showed a high prevalence of rhinitis and infectious bronchitis especially in the city of Ptolemais, and these findings were attributed to the heavy environmental pollution (Sichletidis et al. 2005).

\subsubsection{Metalliferous particles}

The dominant metalliferous airborne particles are iron and copper-rich particles. A single fine copper-rich particle is shown in Figure 4e, and agglomeration of iron oxides, rich in trace metals $(\mathrm{Zn}, \mathrm{Cu})$ is shown in Fig. 5f. These particles are likely to be associated with motor vehicle activity, originating from brake and tyre wear (Cyrys et al. 2003, Arditsoglou and Samara 2005, Lough et al. 2005). Furthermore, Fuge (2005) noted that motor vehicles could be a source of copper pollution, it being released from copper wiring, thrust bearings and brakes.

Of specific concern has been the potential threat posed by exposure to particles containing transition metals. Transition metal toxicity is considered to occur through an oxidative/free radical pathway leading to respiratory inflammation (Fernandez et al. 2002, Powell et al. 2002, Cassoni et al. 2004). The finest fraction of particulate matter deserves special attention for it carries deeply into the lung these adsorbed chemicals (Breed et al. 2002).

\section{Conclusions}

The concluding remarks of the present study are the following:

- ESEM coupled with EDS system helped us to assess qualitatively the contribution of airborne particles of various origin, morphology and composition to the air pollution of Kozani's region.

- The airborne particles were classified as geogenic, biogenic and anthropogenic (mainly fly ash). Quartz, calcite, feldspar, mica, and clays are some of the common minerogenic (natural) airborne particles observed in this study, while diatoms, spores/pollen and fungal spores are some of the biogenic airborne particles identified.

- Characteristic features of fly ash particles were also identified. Fine fly ash particles were found in remote areas, whereas the coarser ones were observed in the vicinity of the power plants. Metalliferous particles (mainly $\mathrm{Fe}$ and $\mathrm{Cu}$-rich particles) were also observed, most likely having a vehicular (exhaust, tyre and brake abrasion) origin.

- A database is being created including ESEM images and EDX spectra of characteristic individual airborne particles from Ptolemais-Kozani area, which could be useful for similar studies in the future.

\section{Acknowledgements}

The financial support of the European Community- Access to Research Infrastructure action of the Improving Human Potential Programme, through a visit at the European Infrastructure for Energy Reserve Optimisation (EIERO, Project HPRI-CT-2001-00173) is gratefully acknowledged. The scientific personnel of the Airlab of TEI of Western Macedonia are also acknowledged for providing the filter samples. Lastly, we are indebted to Dr. Nadja Ognjanova, Bulgarian Academy of Sciences and Dr. Anson W. Mackay, University College London for the identification of the diatoms.

\section{References}

Arditsoglou, A., and Samara, C., 2005. Levels of total suspended particulate matter and major trace elements in Kosovo: a source identification and apportionment study, Chemosphere, 59 (5), 669-678. 
Breed, C.A., Arocena, J.M., and Sutherland, D., 2002. Possible sources of PM10 in Prince George (Canada) as revealed by morphology and in situ chemical composition of particulate, Atmospheric Environment, 36 (10), 1721-1731.

Cassoni, F., Bocchi, C., Martino, A., Pinto, G., Fontana, F., and Buschini, A., 2004. The Salmonella mutagenicity of urban airborne particulate matter (PM 2.5) from eight sites of the Emilia-Romagna regional monitoring network (Italy), Science of the Total Environment, 324 (1-3), 79-90.

Cyrys, J., Stolzel, M., Heinrich, J., Kreyling, W.G., Menzel, N., Wittmaack, K., Tuch, T., and Wichmann, H.E., 2003. Elemental composition and sources of fine and ultrafine ambient particles in Erfurt, Germany, Science of the Total Environment, 305 (1-3), 143-156.

Derbyshire, E., 2005. Natural aerosolic mineral dust and human health. In O. Selinus, et al. (eds), Essentials of Medical Geology; impacts of the natural environment on Public Health, 459480, Amsterdam, Elsevier Academic Press, 832pp.

Ebert, M., Weinbruch, S., Hoffmann, P., and Ortner, H.M., 2004. The chemical composition and complex refractive index of rural and urban influenced aerosols determined by individual particle analysis, Atmospheric Environment, 38 (38), 6531-6545.

Fernandez, A., Wendt, J.O.L., Cenni, R., Young, R.S., and Witten, M.L., 2002. Resuspension of coal and coal/municipal sewage sludge combustion generated fine particles for inhalation health effects studies, Science of the Total Environment, 287 (3), 265-274.

Fernandez-Turiel, J.L., Georgakopoulos, A., Gimeno, D., Papastergios, G., and Kolovos, N., 2004. Ash Deposition in a Pulverized Coal-Fired Power Plant after High-Calcium Lignite Combustion, Energy \& Fuels, 18, 1512-1518.

Fuge, R., 2005. Anthropogenic sources. In O. Selinus, et al. (eds). Essentials of Medical Geology; impacts of the natural environment on Public Health. 43-60, Amsterdam, Elsevier Academic Press, 832pp.

Georgakopoulos, A., Kassoli-Fournaraki, A., and Filippidis, A., 1992. Morphology, mineralogy and chemistry of the fly ash from Ptolemais lignite basin (Greece) in relation to some problems in human health, Trends in Mineralogy, 1, 301-305.

Goforth, M.R., and Christoforou, C.S., 2006. Particle size distribution and atmospheric metals measurements in a rural area in the South Eastern USA, Science of the Total Environment, $356(1-3), 217-227$.

Iordanidis, A., Buckman, J., Mitrou, D., and Asvesta, A., 2005. Characterisation of Greek fly ash using Environmental SEM, Proc. Of the International Workshop in Geoenvironment and Geotechnics, 12-14 September 2005, Milos island, Greece, 171-175.

Jones, T., Moreno, T., BéruBé, K., and Richards, R., 2006. The physicochemical characterization of microscopic airborne particles in south Wales: A review of the locations and methodologies, Science of the Total Environment, 360 (1-3), 43-59.

Kallithrakas-Kontos, N., Zoumi, K., Nikolakaki, S., and Kritidis, P., 1998. Trace elements and radioactivity in aerosol particles, produced in the area of Ptolemais (Greece), Journal of Radioanalytical and Nuclear Chemistry, 227 (1-2), 61-65.

Kantiranis, N., Filippidis, A., Mouhtaris, Th., Paraskevopoulos, K.M., Zorba, T., Squires, C., and Charistos, D., 2006. EPI-type zeolite synthesis from Greek sulphocalcic fly ashes promoted by $\mathrm{H}_{2} \mathrm{O}_{2}$ solutions, Fuel, 85 (3), 360-366.

Kupiainen, K., and Tervahattu, H., 2004. The effect of traction sanding on urban suspended particles in Finland, Environmental Monitoring and Assessment, 93 (1-3), 287-300. 
Lee, S.W., He, I., and Young, B., 2004. Important aspects in source PM2.5 emissions measurement and characterization from stationary combustion systems, Fuel Processing Technology, 85, 687- 699 .

Liao, C-M., Luo, W-C., Chen, S-C., Chen, J-W., and Liang, H-M., 2004. Temporal/seasonal variations of size-dependent airborne fungi indoor/outdoor relationships for a wind-induced naturally ventilated airspace, Atmospheric Environment, 38 (26), 4415-4419.

Lough, G.C., Schauer, J.J., Park, J.S., Shafer, M.M., Deminter, J.T., and Weinstein, J.P., 2005 Emissions of metals associated with motor vehicle roadways, Environmental Science and Technology, 39 (3), 826-836.

Ognjanova-Rumenova, N., 2003. On the micropaleontology and paleoecology of Miocene nonmarine diatoms from Sivik Formation, Satovcha basin, southwest Bulgaria, Phytologia Balcanica, 9 (2), 207-220.

Paoletti, L, De Berardis, B., and Diociaiuti, M., 2002. Physico-chemical characterisation of the inhalable particulate matter (PM10) in an urban area: An analysis of the seasonal trend, Science of the Total Environment, 292 (3), 265-275.

Powell, J.W.D., Hunt, A., and Abraham, J.L., 2002. Anthropogenic vanadium-chromium-iron and cerium-lanthanum-iron particles in settled urban house dust: CCSEM identification and analysis, Water, Air, and Soil Pollution, 135 (1-4), 207-217.

Ryves, D.B., Jewson, D.H., Sturm, M., Battarbee, R.W., Flower, R.J., Mackay, A.W., and Granin, N.G., 2003. Quantitative and qualitative relationships between planktonic diatom communities and diatom assemblages in sedimenting material and surface sediments in Lake Baikal, Siberia, Limnology and Oceanography, 48 (4), 1643-1661.

Samara, C., 2005. Chemical mass balance source apportionment of TSP in a lignite-burning area of Western Macedonia, Greece, Atmospheric Environment, 39 (34), 6430-6443.

Sichletidis, L., Tsiotsios, I., Gavriilidis, A., Chloros, D., Gioulekas, D., Kottakis, I., and Pataka, A., 2005. The effects of environmental pollution on the respiratory system of children in Western Macedonia, Greece, Journal of Investigational Allergology and Clinical Immunology, 15 (2), 117-123.

Stalikas, C.D., Chaidou, C.I., and Pilidis, G.A., 1997. Enrichment of PAHs and heavy metals in soils in the vicinity of the lignite-fired power plants of West Macedonia (Greece), Science of the Total Environment, 204 (2), 135-146.

Suzuki, K., 2006. Characterisation of airborne particulates and associated trace metals deposited on tree bark by ICP-OES, ICP-MS, SEM-EDX and laser ablation ICP-MS, Atmospheric Environment, 40 (14), 2626-2634.

Triantafyllou, A.G., 2001. PM10 pollution episodes as a function of synoptic climatology in a mountainous industrial area, Environmental Pollution, 112, 491-500.

Triantafyllou, A.G., Kiros, E.S., and Evagelopoulos, V.G., 2002. Respirable particulate matter at an urban and nearby industrial location: Concentration and variability and synoptic weather conditions during high pollution episodes, Journal of Air and Waste Management Association, 52, 287-296.

Zoras, S., Triantafyllou, A.G., and Evagelopoulos, V., 2006. Modelling of PM2.5 episodes in four cities of Northwestern Greece, Fresenius Environmental Bulletin, 15(4), 306-313. 